\title{
Music in a Concussive Monologue
}

\author{
Simon Gilbertson ${ }^{1}$, David Gabriel Hebert ${ }^{2}$ * \\ 1 Grieg Academy-Dept. of Music, University of Bergen, Norway \\ 2 Western Norway University of Applied Sciences, Norway \\ *dgh@hvl.no
}

Received: 8 April 2021 Accepted: 25 August 2021 Published: 1 November 2021

Editor: Tanya Marie Silveira Reviewers: Maevon Gumble, Alex Street

\section{Abstract}

The co-authors, a music therapist and a musicologist who suffered a concussion, collaboratively develop an autoethnography detailing the phenomenological experience of concussion and the gradually increasing role of music throughout the recovery process. Along the way, they discover new things about music, the mind, scholarship, and themselves.

Keywords: head injury, concussion, autoethnography, collaborative writing

\section{Prelude}

Sometime in October 2016, two colleagues in deep discussion...

"What about David? I was wondering if we could have him as a keynote speaker?"

"He hasn't been really very well Simon" Jill replied. "Perhaps you haven't heard. Something happened with his head. He's been away from work for quite some time now."

“That's a pity. It would have been great. Do you remember he was my respondent when I gave that quirky presentation, 'Music therapy for the inseparable human.' His comments were a gift on that day."

"Yes, I got a sense that he found something useful somewhere in what you'd said."

"I wonder how he's doing."

Quietly, Simon's mind raced-with concerns for David, and also flashbacks from nearly two decades of music-making with people affected by severe traumatic brain injury in early neurosurgical rehabilitation. , $2,3^{2}$

Many months later, David and Simon at a research seminar dinner...

"You know Simon, I think I have something we might talk about. Well, you know that I experienced severe concussion from a fall a while back?"

"I heard about that, David. We should try and find a time to talk soon when the seminar is over." 
Some months later and an introduction to the text...

Far from any treatment center or therapy room context we met via Zoom on five occasions in Spring 2021 for extended conversations. As two friends and professionals with experience in music performance, composition, education, therapy and research we explored the intersections of concussion, music and recovery in a collaborative, conversational and co-constructive process which we document here. We both shared the sense that this exploration felt worthy particularly in the light of the counted and uncounted millions of people every year that suffer concussion throughout the world, through war and violence, sports and hobbies, and everyday incidences like tripping and falling. ${ }^{4}$

The text is an intentional experiential narrative that we created collaboratively. Some qualities of disorientation and dislocation may be experienced when reading. The voicing shifts at times between us invisibly, the text fluidly moving between David's description of the events and Simon's witnessing of these descriptions. In contrast to a single-person autoethnography, the process of further developing the manuscript, engaging with the reviewers' supportive and helpful suggestions, and finalizing the text has been done dialogically. We add imagined both future injured ("I") and future caregivers ("you") at different points to highlight some of the ways we have experienced that care is needed in engaging with music after concussion. We have marked the sections regarding future injured and care-givers in italics. We end by sharing core aspects of our learning and remaining questions so far.

Some weeks later, notes from our Zoom sessions take shape, emerging as a musical autoethnography ${ }^{5}$...

\section{A monophonic monologue}

He is only 4 years old. He knows no different.

He shoots up the concrete steps, disappears through the shady bushes onto the busy road chasing his older cousins, squawking in each other's delight. I lurch through the house, scream after his presence, and chase the remnants of his voice. The California sun blinds my retinal control. The ground parts away from my poorly shod feet, no time for laces. Falling, failing. Have I failed my son? He knows no different. A nuclear bomb goes off in my head. The concrete step is oblivious to the contrecoup injury it inflicts to my brain. Motionlessly rising it crushes the sense of self out of me. My soul's habitat is deleted temporarily without me being informed in advance. It's unbelievable, earth-shattering, like what the end of the world would sound like. I reach up to my head sure that my brain is starting to pour out. I sense I may only have a few more seconds. Such a shame, really. Things had only just started to turn out good in my life. I crawled. I called.

Bled, bandaged. My parents, sister and various doctors helped me. They said I needed rest and needed to be patient. They couldn't say for how long. I was grateful and relieved my son was fine. After a miserable journey back from the USA, I somehow returned to my Norwegian dwelling. It was new, tiny, foreign, and pain-filled, with complete isolation. No wife (divorced), no child (doing fine with his mother), no parents (still in California). No colleague (off-work), no self. That self could not be located. Not yet. Still dislocated by concussion. The pain increased steadily over the first weeks. Incessant, relentless pain. I wasn't able to sleep. I was so scared that I wouldn't wake up again if I did. I hallucinated a cartoon-shaped golden lightning bolt in front of my eyes that would never go away. Imagine that. 


\section{The first 50 days at zero beats per minute}

Darkened, silenced, huddled away from painful stimuli of all types. Music soothes not this soul. Not now. Dark glasses, shooting range ear protectors.

I no longer knew how to make that food where you put something in-between something like bread. It was too difficult. I just went back to bed hungry. Sometimes, in a time-window of about 40 minutes each day, I felt strong enough to get up. But I was unsure of the route along one single road; just back and forth from my home to the grocery store, and back again. On one occasion, during the return, I stood on the spot looking around without knowing what I was searching for. I walked straight ahead and was lucky to get home.

Somehow, as a result of the fall, I disappeared from myself. I was inside of a body that looked familiar, but I didn't recognize myself by my thoughts, or my ideas, or capabilities. The real me was gone and I missed him. I yearned. I wanted to get back to normal. To find myself. I couldn't figure out where I was. Imagine that.

I tried listening to music, but immediately experienced pain. I just wanted anesthetic sounds that would help me easily let the few hours that I was awake, or at least barely mentally functioning, to go by as quickly as possible. I just wanted to get through as many days as quickly possible. All music was pain-ridden.

I returned to silence.

\section{The next 50 days}

Concussion, confusion, dis/location. Calling out to you for sensorially-attuned companionship.

At recovery's rubato, without cadence or harmonies stealing my momentary grasp on reality. One note at a time, a pause, and then the next. That was the limit. Drones and harmonium. Breath and silence. These were the only ways to musically locate myself and find refuge from pain.

My inner-voice relentlessly repeated, "I can't continue like this. I can't find me".

I couldn't read. Audio books were fine as long as the stories were short. Raymond Carver, Chekhov, Tolstoy, Maupassant, and Borges. One story per day. Maybe. Ernst Hans Josef Gombrich's A Little History of theWorld ${ }^{6}$ reminded me that it is important to hear about people that I had never heard much about, like the Peloponnesians. Imagine them.

I had some good days when sounds that attuned to my attentional progression were welcome. There is still so much to learn about how pain is elicited by music content, structure and form. Between all the other sounds and my mind, I placed the industry's finest noise-cancelling headphones. Music's ubiquitous nature is cancelled. Noise cancelled.

My pain-directed stillness may seem wrong to you and in need of activation by stimulation and training. My pain-directed stillness calls you, however, to place your prescription protocol for "orientation and activation" elsewhere. It's not my previous musical preference that you need to find out, it is my current musical state.

And here is my challenge to you: I know where I am-I am there where I cannot be found and it is there that I need you to help to look with me. That is the orientation that you will require to join me and others in the process of recovery. I need you to find me in the musical place in which I am, in this present.

I first looked for anesthetic sounds-ones that removed my consciousness. Music that did not destruct my capacity of attention, but then I looked for analgesic music that 
could help lessen the pain I was experiencing. I looked for those tunes in the minutes and hours each day that I was surviving well.

This is the tune, the timbre, the timing that I-and you-need. Join me in my temporal survival of pain.

I would have wished to have someone who could have joined me in my nuanced interest in the layers and shifting leaves of David Sylvian's shifts with Holger Czukay in Flight and Premonition, ${ }^{7}$ with Arvo Pärt's breathing in Für Alina, ${ }^{8}$ Hindustani drones in my brain, ${ }^{9}$ and Dali's melting clocks in his painting, The Persistence of Memory. ${ }^{10}$ Harold Budd's "As Long as I Can Hold my Breath"11 gifted me the space I needed to be able to listen without increasing pain and suffering. These were the musics and sights of my recovery.

The music, and the slow tempo, hinted at my need for a different sense of time. More importantly I experienced music of a different sense of acceptance. The music aided me in not being so angry and frustrated-it gave me the sense that it's okay to be in this very slow groove. Somehow the music was needed to help reinforce the idea, "You are stuck here, and it is okay for now."

The apparent idiosyncrasy of peoples' needs of music during recovery and care are mistakenly narrated as they are based only on visible observations. At an invisible musicological level, the need for timelessness is congruent with the timelessness of recovery and lack of bar lines in the nature of change and acceptance...

So, I ask you to imagine something else.

Leave your claims of the nature of music's languages. Or your random control.

Sing with my cries of loss that are for the person I cannot help you locate.

He is that person.

He is that person who is not there.

You will not find him in your simple bars, nightclubs, or pounding beats of social time-wasting.

Do not bang around on inclusions' drums for the concussed. For the percussive is as concussive as it is discursive. What the concussed human needs is selective and dialogical shared attention. The most important thing for a healthy, functioning brain to do is not to pay attention to everything.

I had lost control of my ability to concentrate, to ignore, and to get my brain to selectively attend to that thing that matters at that time. You can't listen to rhythmic music when you can clearly hear the rasping sounds made by the legs of a fly on a window at the opposite side of the room. I could only let a small amount of matter into my brain's nuclei. A quantum at a time.

The tempo of recovery is known only by the improvisatory unfolding of incomplete attempts of utterance. It must be possible to reject one's own attempts of attention and choice. To end listening when it mutates into pain without anyone else noticing. It is like the phraseology of those first tears and cries of failing, of falling. With the hard concrete step of the initial fall no longer before me, it is a continuous falling forward. A sequence of failed closure, cadential interruptions layered upon cadential interruptions that match painlessly the scope of attention that is gradually convalescing, quietly, and at the speed of consistent pain.

Even though I was making minute progression, there was no scope for joy. The rejection of joyous frivol during concussion is not caused by the sadness of a broken heart 
however, but by the resilience of throbbing minds in the unending course of every solo attempt uncompleted.

"But there are things to be done and I can't be patient," I cry.

“There are people relying on me! I can't wait any longer to for my life to begin again if you're not recognizing that this is how my life is progressing."

\section{Beyond the first 100 days}

Over time, slowly, the concussive disordering calms and, in time, but long overdue, the pain resides and I emerge to myself through myself. The lightning bolt hallucination unnoticedly disappeared. It was probably only a blond eyebrow hair hanging far down into my eye all the time anyway.

Work resumed, the load picked up, edited books became published, concerts given, positive reviews from students again. It becomes possible to judge that things are once more fine. I know which end of the street is home.

In company and conversation, the shifts forward are accompanied in embodied resonance. Finally witnessed via Zoom. The incredible slowness of the recovery, the recovery of each slither of light, each nanosecond of sonic data of esthetic. Noted, followed, felt, transcribed.

We asked each other whether it could be musics' role in this narrative to live responsively with the person with concussion? Shouldn't music help people understand more together, with another, about another, for another? Can we develop the sharing of interest in how the beginning, middle, and end of a single breath has an inseparability with the beginning, middle, and end of a North Indian improvisation, a single note on the shakuhachi flute, or the albums Stan Getz with Strings ${ }^{12}$ or Miles Davis's In a Silent Way ${ }^{13}$ in understanding a concussive monologue through musicological attention? Should compositional attention to music and sound attract and establish a mutual immersion in recovery and care, idiosyncrasy and togetherness, conversing and writing?

We thought so.

And then more questions whisper in warm breath between us, "What have You learned? What can I learn?"

Well, we get on with the learning that lies further ahead and begin at, or as David Boje suggests, begin before the beginning, searching out the ante-narrative. ${ }^{14}$ Share, re-iterate. Play the trumpet again. Sing with my full voice. Be a person for others. Make a contribution that benefits others. Be a fragile human amongst others. Be a musician. Be writers together.

\section{What next?}

There are many pathways in learning about concussion, music, and caring for oneself and others outside of therapy and within therapy. Similarly, there are many open avenues for future research, practice development and public discourse that may be explored.

Early on in this process we experienced that it is important not to wait to find time, but to establish and secure time for exchanges between those who have experienced concussion and those who care for people who have experienced concussion.

We have also learnt that our convergence as two musicians, researchers, and teachers affords the opportunity to learn more about the presence and absence of concurrent multiple theoretical layers of discourse about music and health. 
We have strongly felt the need to better understand idiosyncrasy through the sharing of re-educative examples, and the politics of variability and difference. ${ }^{15}$

We feel that there is an acute need for musicians and music therapists to consider and examine the significance of extreme slowness as an unavoidable pre-requisite for the development of the arts, health care and contemporary society (beyond immediate emergency response situations). Long term attention needs to be given to those recovering and to extremes of idiosyncratic temporality. Through these opportunities we sense the importance of more actively seeking out community with those who hold phenomenological insights into ontological diversity. ${ }^{16,17}$

We have also experienced a shift toward creative autoethnographic writing away from an epistemological research commitment that might search for "elicited" categories in transcripts. This new approach invites expression of ontological exploration and critical reflexivity. ${ }^{18,19}$ As scholars choosing creativity, we will at times also trust the pen in nights of doubt. $5,20,21,22$

We have experienced the significance of taking time to be with those who have concussion and those who chose to care for them. We have experienced the significance of immersing ourselves in the listening choices of others. We have been challenged to pause our own musicological consciousness, and learn more about the idiosyncratic neurological improvisation of recovery, and are grateful to be able to contribute to the thousand-year-old musical narrative ${ }^{23,24,25}$ of recovery and concussion.

\section{About the authors}

Simon Gilbertsonis an Associate Professor of Music Therapy with the University of Bergen, Norway, where he leads the Grieg Research School for Interdisciplinary Music Studies. He serves on several editorial boards, is a contributor to major research handbooks, and co-author of the book Music Therapy and Traumatic Brain Injury: A Light on a Dark Night.

David G. Hebert is a tenured Professor of Music at Western Norway University of Applied Sciences (Bergen), where he leads the Grieg Academy Music Education (GAME) research group. He is manager of the Nordic Network for Music Education, Professor II at Lund University, and Honorary Professor with the Education University of Hong Kong.

\section{References}

1. Gilbertson, S. (2008). The silent epidemic of road traffic injury: What can music therapists do about it? Voices: A World Forum for Music Therapy, 8(1). https://doi.org/10.15845/ voices.v8i1.448

2. Gilbertson, S. (2016). Music therapy and traumatic brain injury. In J. Edwards (Ed.), Oxford handbook of music therapy (pp. 362-383). Oxford University Press.

3. Gilbertson, S., \& Aldridge, D. (2008). Music therapy and traumatic brain injury: A light on a dark night. Jessica Kingsley Publishers.

4. Mullally, W. J. (2017). Concussion. American Journal of Medicine, 130(8), 885-892. https://doi.org/10.1016/j.amjmed.2017.04.016

5. Lee, K. V. (2010). An autoethnography: Music therapy after laser eye surgery. Qualitative Inquiry, 16(4), 244-8. https://doi.org/10.1177/1077800409351975

6. Gombrich, E. H. J. (2005). A little history of the world (C. Mustill, Trans.). Yale University Press. (Original work published 1935)

7. Sylvian, D., \& Czukay, H. (1988). Plight and premonition [Album]. Venture Records.

8. Pärt, A. (1999). Für Alina [Album recorded by Alexander Malter]. ECM Records. (Original work published 1976) 
9. Sanyal, S., Nag, S., Banerjee, A., Sengupta, R., \& Ghosh, D. (2019). Music of brain and music on brain: A novel EEG sonification approach. Cognitive Neurodynamics, 13(1), 13-31. https://doi.org/10.1007/s11571-018-9502-4

10. Dali, S. (1931). The persistence of memory [Oil on canvas]. Alfred H. Barr, Jr. Galleries, MoMA, Floor 5, 517, Manhattan, New York, NY.

11. Budd, H. (2005). Avalon Sutra/As long as I can hold my breath [Album]. Darla Records.

12. Getz, S. (1960). Cool velvet: Stan Getz with strings [Album]. Verve Records.

13. Davis, M. (1969). In a silent way [Album]. Columbia Records.

14. Boje, D. M. (2001). Narrative methods for organizational and communication research. Sage Publications.

15. Hebert, D. G., \& Rykowski, M. (Eds.) (2018). Music glocalization: Heritage and innovation in a digital age. Cambridge Scholars.

16. Gilbertson, S. (2019). Imagining something else: A queer essay. Voices: A World Forum for Music Therapy, 19(3). https://doi.org/10.15845/voices.v19i3.2702

17. Hebert, D. G. (2009). Musicianship, musical identity and meaning as embodied practice. In T. Regelski \& J. T. Gates (Eds.), http://www.springer.com/education + \%26 + language/ professional +\%26 + vocational + education/book/978-90-481-2699-6 (pp. 39-55). Springer Publishing.

18. Ellis, C. (2000) Creating criteria: An autoethnographic short story. Qualitative Inquiry, 6(2), 273-277. https://doi.org/10.1177/107780040000600210

19. Plummer, K. (2001). The call for life stories in ethnographic research. In P. Atkinson, A. Coffey, S. Delamount, J. Lofland, \& L. Lofland (Eds.), Handbook of ethnography (pp. 395-406). Sage Publications.

20. Osborn, C. L. (1998). Over my head: A doctor's own story of head injury from the inside looking out. Andrews McMeel Publishing.

21. Sinner, A., Hasebe-Ludt, E., \& Leggo, C. (2018). Long story short: Encounters with creative nonfiction as methodological provocation. In P. Leavy (Ed.), Handbook of arts-based research (pp. 165-189). Guilford Press.

22. Lee, K. V., \& Gouzouasis, P. (2017). Tommy's tune: Autoethnographic duet. Qualitative Inquiry, 23(4), 316-320. https://doi.org/10.1177/1077800416659081

23. Horden, P. (Ed.) (2016). Music as medicine: The history of music therapy since antiquity. Routledge.

24. Sidik, R., Kamaruzaman, A. F., \& Abdullah, M. J. (2021). Music therapy in medicine of Islamic civilisation [Online First], IntechOpen. https://doi.org/10.5772/intechopen.98707. Available from https://www.intechopen.com/online-first/77311

25. Vallat, P. (2011). al-Fārābī, Abū Naṣr. In H. Lagerlund (Ed.), Encyclopedia of Medieval Philosophy. Springer Publishing. https://doi.org/10.1007/978-1-4020-9729-4_165 